Article

\title{
Experimental Investigation of Sludge Treatment Using a Rotor-Stator Type Hydrodynamic Cavitation Reactor and an Ultrasonic Bath
}

\author{
Hyunsoo Kim ${ }^{1} \mathbb{D}$, Xun Sun ${ }^{2}$, Bonchan Koo $^{1} \mathbb{( \mathbb { C }}$ and Joon Yong Yoon ${ }^{1, *}$ \\ 1 Department of Mechanical design Engineering, University of Hanyang, Seoul 04763, Korea; \\ khs0213khs@hanyang.ac.kr (H.K.); b98265300@gmail.com (B.K.) \\ 2 Key Laboratory of High Efficiency and Clean Mechanical Manufacture, Ministry of Education, \\ National Demonstration Center for Experimental Mechanical Engineering Education at Shandong University, \\ School of Mechanical Engineering, Shandong University, Jinan 250061, China; xunsun@sdu.edu.cn \\ * Correspondence: joyoon@hanyang.ac.kr; Tel.: +82-31-400-5282; Fax: +82-31-400-4707
}

Received: 25 September 2019; Accepted: 25 October 2019; Published: 1 November 2019

\begin{abstract}
In the present work, the sludge treatment performance of a sludge treatment using a rotor-stator type hydrodynamic cavitation reactor (HCR) was investigated. To verify the performance, a comparison with an ultrasonic bath was conducted in four experimental cases using three assessment factors. The HCR consisted of a rotor and three covers with inserted dimples resulting in variation of the cross-sectional area in a flow. The experimental cases were established using the same energy consumption for each device. Disintegration performance was analyzed with assessment factors using particle size distribution and sludge volume index (SVI), oxidation performance using total chemical oxygen demand (TCOD) and volatile suspended solids (VSS) reduction rate, as well as solubilization rate using soluble chemical oxygen demand (SCOD). As a result, the particle disintegration and oxidation performance of the HCR were generally superior to those of the ultrasonic bath. However, due to the contradictory interactions of these factors, the solubilization rate of the two devices was measured similarly as $42.3 \%$ and $41.4 \%$ for each device. Results of the current study proved that the HCR can be an effective, promising and clean sludge treatment technique for use in wastewater treatment plants.
\end{abstract}

Keywords: rotor-stator type hydrodynamic cavitation reactor; ultrasonication; sludge treatment; performance comparison

\section{Introduction}

Environmental pollution has become a serious global problem due to continuous industrialization. Especially, water pollution is a major issue, and regulations for waste-water disposal are being reinforced globally. Consequently, waste-water treatment methods that are both environmentally friendly and effective have become critical needs [1-4]. In industrial and municipal waste-water treatment plants (WWTPs), the activated sludge treatment method is the most used biological process. However, this method produces a high amount of excess sludge consuming $18 \%-57 \%$ of total operational cost of WWTPs. To reduce the amount of excess sludge, various techniques have been used to treat waste-water for decades. However, traditional methods generally involve a high processing cost, long treatment time, low treatment capability, or generation of chemical by-products [5]. To overcome these drawbacks, new methods have been proposed in the literature [6-9]. Among them, cavitation has shown a remarkable development potential for large scale applications.

Cavitation refers to the process of bubble generation, growth, and collapse in a liquid due to local pressure drop. The bubble generated by cavitation grows through heat transfer from the nearby liquid. 
When it reaches maximum size, it collapses releasing tremendous energy in the form of heat and a shockwave that imparts the three following effects $[10,11]$. The first is the physical effect. When the bubble collapses, a shock wave of $550 \mathrm{MPa}$ is emitted at a speed of $2000 \mathrm{~m} / \mathrm{s}$, a micro jet generates a $450 \mathrm{MPa}$ water hammer at $100 \mathrm{~m} / \mathrm{s}$, and shear stress reaches $3.5 \mathrm{kPa}$. The second is a thermal effect. The collapse of the bubble generates a local hot spot of $2000-6000 \mathrm{~K}$ and induces $10^{10} \mathrm{~K} / \mathrm{s}$ heat transfer within one microsecond. The third is a chemical effect. Due to the energy generated by bubble collapse, water molecules are decomposed into $\mathrm{H} \cdot$ and $\mathrm{OH} \cdot$, the latter is a strong oxidizing agent, and these effects can treat the sludge. The physical effect of cavitation leads to disintegration of particles and lysis of microorganisms resulting in enhancement of biogas production during anaerobic digestion of biomass [12]. The thermal effect improves the dewaterability of the sludge and reduces the sludge's viscosity by causing cell lysis and destroying the cell walls [13]. In the case of the chemical effect, the free radicals generated by cavitation accelerate chemical reactions and inactivate and remove microorganisms through decomposition of hydrogen bonds [14,15].

Cavitation can be classified as a method inducing pressure perturbation in a liquid. Ultrasonic cavitation (UC) occurs due to the pressure perturbation by ultrasound waves. When ultrasound waves propagate in a liquid medium, the liquid molecules repeatedly contract and expand. In the contracting cycle, the liquid pressure increases, while in the expanding cycle it decreases [16]. The ultrasonic cavitation reactor (UCR) has a simple structure and easily generates bubble; hence, it has been used to treat sludge [17]. However, UCR has much low energy transfer efficiencies $(10 \%-40 \%)$, and the cavitation intensity rapidly decreases with distance from the ultrasonic generator $[18,19]$. Hence, an ultrasonic cavitation reactor has poor scalability and is unable to treat the sludge uniformly. On the other hand, hydrodynamic cavitation ( $\mathrm{HC}$ ) occurs due to the pressure perturbation induced by changes in the cross-sectional area. For an incompressible fluid, the flow rate is calculated as the product of cross-sectional area and velocity. When the cross-sectional area decreases at constant flow rate, the fluid velocity increases, by Bernoulli's equation, the pressure decreases. The hydrodynamic cavitation reactor $(\mathrm{HCR})$ induces cavitation using this phenomenon, and due to the generation mechanism, all fluids pass through the cavitation generation region and can be treated uniformly $[19,20]$. The HCR can be classified by way of changing the cross-sectional area. The non-rotation type of HCR lets liquid pass through vena contracta, e.g., the Venturi tube. The rotation type of HCR changes the cross-sectional area using a rotor with an uneven surface, e.g., a shockwave power reactor [21-23]. In most literature focusing on waste-water treatment using HC, non-rotation types of HCRs have been utilized. However, to induce sufficient pressure drop, a high-power pump is required, resulting in a substantial cost. In addition, due to the poor cavitation intensity, it needs long treatment times and shows low treatment performance [24-26]. On the other hand, the rotor-stator type HCR could overcome such limitations. First, since the rotor-stator type HCR is based on HC, waste-water could be treated uniformly. Also, the rotor-stator type HCR changes cross-sectional area repeatedly using rotation, hence the cavitation region and cavitation intensity are much larger than with the non-rotation type HCR. Some research groups have studied the potential for utilizing this technique for water treatment [19,21-23,27-33].

The development of new highly effective HCR is the key to large-scale commercial applications of waste activated sludge (WAS) disintegration. Various types of conventional HCR such as Venturi, orifice, high-pressure jet, Ecowirl, and high-pressure homogenizer have been widely studied to evaluate their effectiveness [34-44]. These devices obtained limited disintegration performance (disintegration degrees $\left(\mathrm{DD}_{\mathrm{cod}}\right)$ of $\left.7.7 \%-31 \%\right)$ with a considerable treatment duration (several hours). On the other hand, rotor-stator type HCR showed a performance which is far higher than the conventional device, the device proposed by Petkovšek et al. [45] easily achieved $57 \%$ of $\mathrm{DD}_{\text {cod }}$ for only 20 passes, without any structure optimization. However, the research on rotor-stator type HCR is still very limited, which largely hinders the commercial application of HC sludge treatment. To the best of our knowledge, the comparison of the disintegration performances between rotor-stator type HCR and $\mathrm{UCR}$ at the same energy consumption has not been investigated. 
The aim of this study was to verify the sludge treatment performance of rotor-stator type HCR and to demonstrate its viability as a real sludge treatment device. The sludge treatment performance depends on the characteristics of the substance requiring treatment [46,47]. In light of this, to evaluate the sludge treatment capabilities of rotor-stator type HCR, comparisons of performance with existing techniques should use the same substance. In the present work, the sludge collected at a sewage treatment plant was treated using a rotor-stator type HCR and an ultrasonic bath. The treatment performance of the HCR and UCR containing decomposition, oxidation, and solubilization performances were compared by analyzing particle size distribution, sludge volume index (SVI), total chemical oxygen demand (TCOD), volatile suspended solids (VSS), and soluble chemical oxygen demand (SCOD) under the same energy consumption.

\section{Experimental Methods}

\subsection{Rotor-Stator Type Hydrodynamic Cavitation Reactor}

The HCR was constructed using the knowledge and results from a previously designed cavitation reactor [48]. Since HCR generates bubbles using pressure perturbation induced by variations in cross-sectional area in the flow path, 32 dimples were located on each surface of a rotor and three covers. The rotor and rear cover were made of stainless steel, while the front and side cover were made of transparent polycarbonate to observe generation of cavitation. The shapes of the rotor and covers are shown in Figure 1. To allow all fluids to uniformly pass through the cavitation region, the inlet is located at the center of the front cover, and the outlet is located at the rear cover. Due to the flow path, all liquids pass through three cavitation generation regions and are treated uniformly.

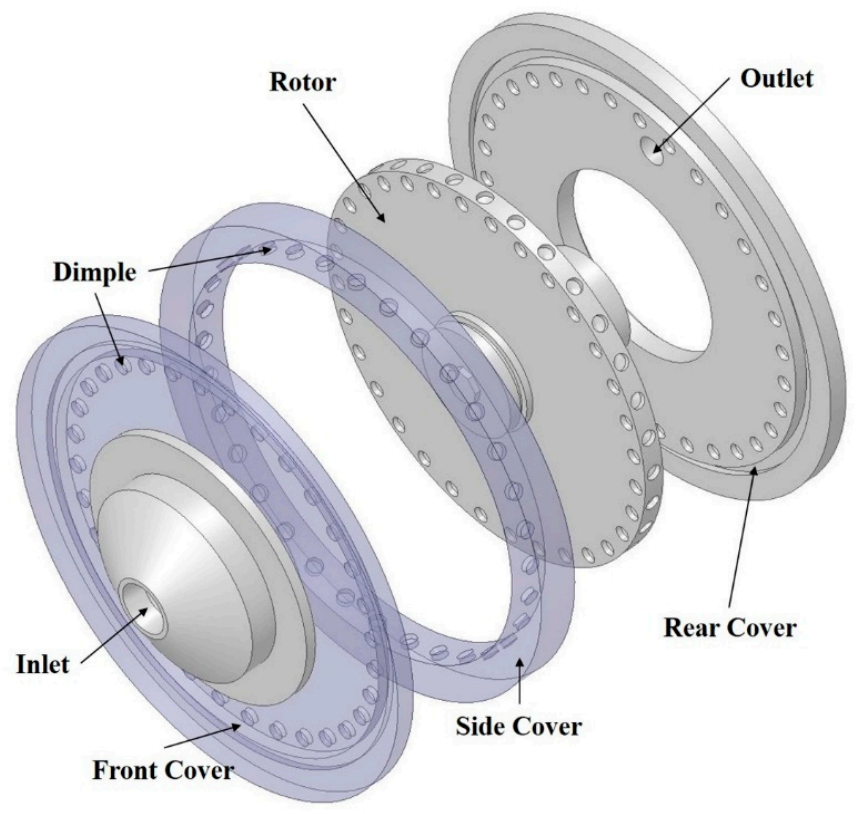

Figure 1. Shape of the rotor and three covers.

To turn the rotor, an electrical motor was used. To measure the electric power consumption of the motor, a clamp-on power meter was utilized. The flow rate was measured by an electromagnetic flow meter. All flow rate signals were collected and transformed to digital signals using a data acquisition (DAQ) board. Signals were saved in a computer using LabVIEW (National Instruments Co., Austin, Texas, USA). The sludge treatment system was assembled as a circuit system without temperature regulation using a reservoir, an inverter pump, and the HCR. A schematic of the HCR treatment system is shown in Figure 2. 


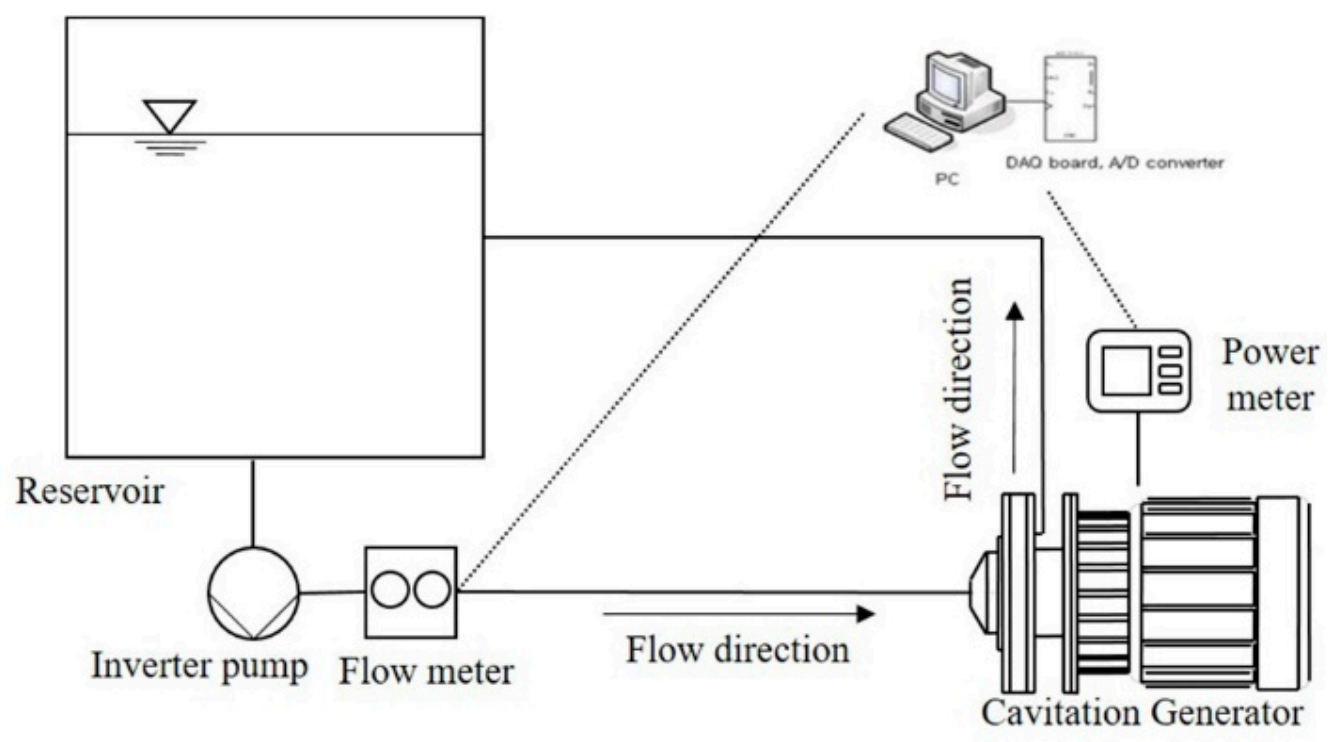

Figure 2. Schematic of the hydrodynamic cavitation treatment system.

\subsection{Ultrasonic Bath}

The general ultrasonic bath, which has eight ultrasonic terminals on the bottom, was used to provide ultrasonic sludge treatment and is shown in Figure 3. Since maximum floc size reduction and increase in solubilization rate are obtained at low frequencies $[49,50]$, the operating frequency was set to $28 \mathrm{kHz}$, and only the operating time was regulated in order to produce the same energy consumption as imparted with the HCR treatment.

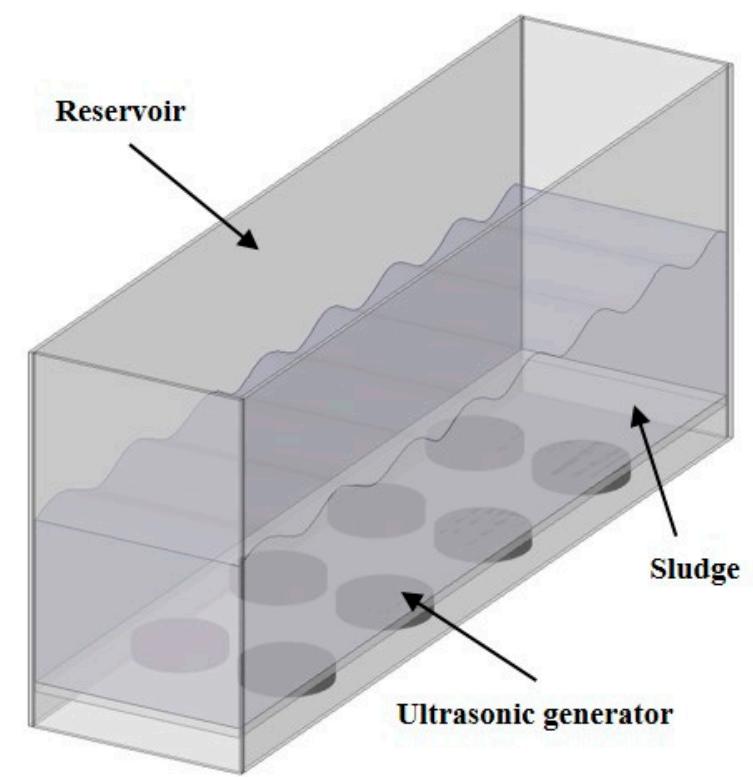

Figure 3. Shape of the ultrasonic bath.

\subsection{Properties of Sludge}

In this study, secondary sewage sludge was obtained from a bioreactor from the Gulpo River Waste-Water Treatment Plant (Bucheon, Republic of Korea). The sludge was stored at $4{ }^{\circ} \mathrm{C}$ for $24 \mathrm{~h}$ prior to experimentation to avoid changes in physicochemical properties and to stabilize the sludge. The properties of the sludge are shown in Table 1. 
Table 1. Waste activated sludge characteristics.

\begin{tabular}{ccc}
\hline Characteristics & Unit & Value \\
\hline $\mathrm{pH}$ & - & 6.48 \\
Total chemical oxygen demand & $\mathrm{mg} / \mathrm{L}$ & 4480 \\
Soluble chemical oxygen demand & $\mathrm{mg} / \mathrm{L}$ & 34 \\
Volatile suspended solids & $\mathrm{mg} / \mathrm{L}$ & 2120 \\
Total solids & $\mathrm{mg} / \mathrm{L}$ & 3726.5 \\
\hline
\end{tabular}

\subsection{Experimental Cases}

To compare the sludge treatment performance of the HCR with that of an ultrasonic bath, four experimental cases were established of energy consumption. The specific energy input [51] which indicates energy consumption of the four experimental cases was calculated using consumed energy every time the sludge passed through the HCR, which occurred five times. The number of passes was calculated using the total sludge amount and flow rate. To exclude other parameters affecting cavitation intensity, the rotational speed and pressure were fixed. The experimental cases are shown in Table 2.

Table 2. Operational conditions of experimental cases.

\begin{tabular}{cccc}
\hline & Specific Energy Input (kJ/kgTS) & Number of Passes (HCR) & $\begin{array}{c}\text { Ultrasonication Time } \\
\text { (Ultrasonic Bath) }\end{array}$ \\
\hline Case 1 & 84,530 & 5 & 26 min $15 \mathrm{~s}$ \\
Case 2 & 167,718 & 10 & $52 \mathrm{~min} 5 \mathrm{~s}$ \\
Case 3 & 248,491 & 15 & $1 \mathrm{~h} \mathrm{17} \mathrm{min} 10 \mathrm{~s}$ \\
Case 4 & 329,800 & 20 & $1 \mathrm{~h} 42 \mathrm{~min} 25 \mathrm{~s}$ \\
\hline
\end{tabular}

\subsection{Analytical Methods}

The particle size distribution was measured using a particle size analyzer (Malvern Co. Mastersizer 2000, Malvern, United Kingdom). Samples were diluted using tap water before analysis owing to the concentration limits of the analyzer, and five measurements were performed for each sample. The particle size distributions were expressed as a volume fraction graph (total area was constant) and percentile particle sizes (in micrometers) corresponding to $10 \%, 50 \%$, and $90 \%$ in a size histogram; the smallest $10 \%, 50 \%, 90 \%$ of the particle diameters were represented as $\mathrm{d}(0.1), \mathrm{d}(0.5)$, and $\mathrm{d}(0.9)$, respectively.

The TCOD and SCOD were measured using COD digestion vials and a visible spectrophotometer (Hach Co., DR3900, Loveland, Colorado, USA) according to the HACH 8000 method. To measure the TCOD, the samples were diluted with distilled water owing to the range of the vials, and the TCOD was expressed as the original value considering the dilution. Additionally, to measure the SCOD, the samples were filtered and not diluted. The samples were heated at $150{ }^{\circ} \mathrm{C}$, for $2 \mathrm{~h}$ using a digital reactor (Hach Co., DRB200, Loveland, Colorado, USA) for the measurements. Five measurements were performed for each sample, and the results were averaged.

Finally, the SVI was visualized for $100 \mathrm{~mL}$ of sludge stored for $30 \mathrm{~min}$ using a mass cylinder.

\section{Results and Discussion}

\subsection{Decomposition Performance}

To evaluate the sludge particle disintegration performance of the HCR, the particle size distribution was measured. The particle size of the sludge is closely related to anaerobic digestion performance and dewaterability. Smaller sludge particle size improves anaerobic digestion performance and dewaterability by transforming the bound water to free water [52-54]. Disintegration of the particles via cavitation proceeds physically by shear stress and chemically due to the $\mathrm{OH}$. [55-57]. In this section, using a comparison of particle size distribution with ultrasonication, the disintegration performance 
of the HCR was evaluated. In each experimental case, the particle size distributions of three types of sludge; raw sludge, sludge treated by the HCR, and sludge treated by the ultrasonic bath are shown in Figure 4.
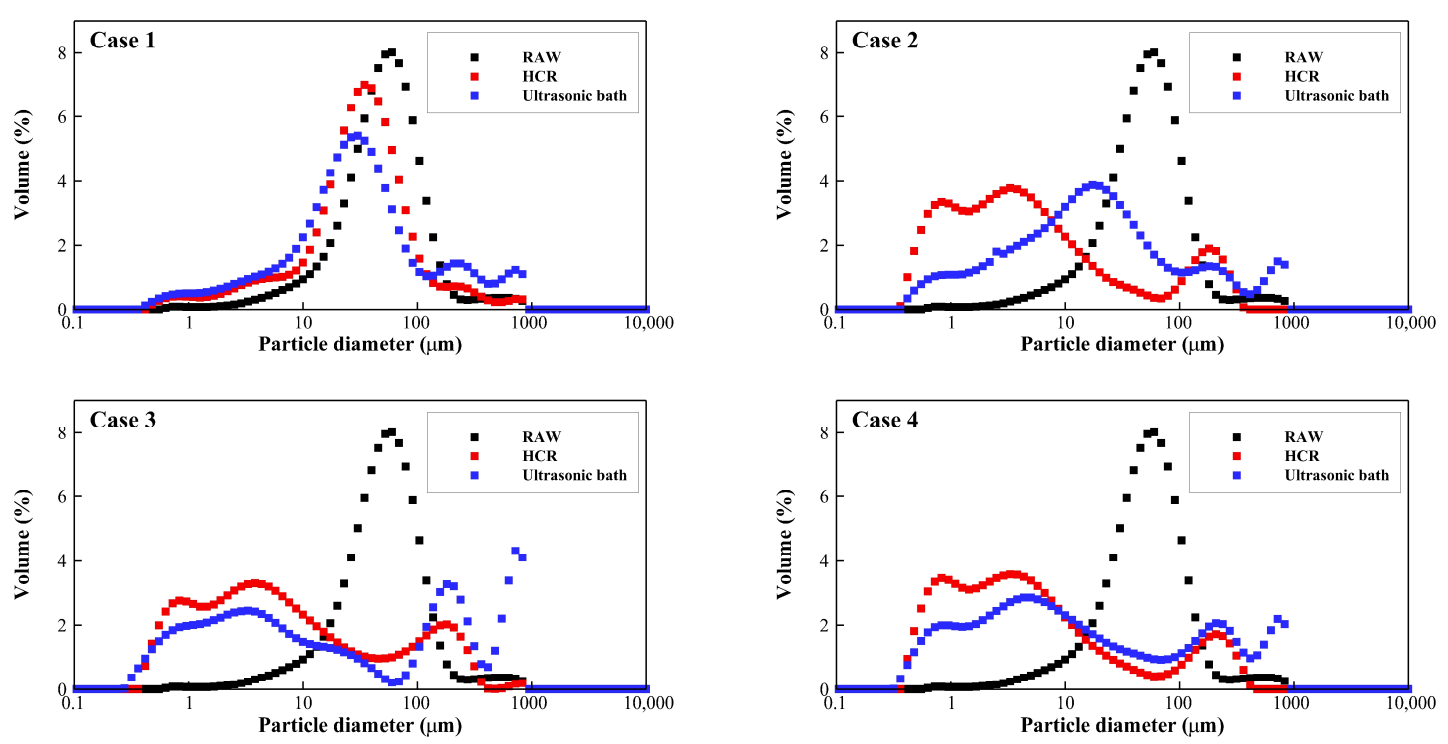

Figure 4. Particle size distributions for the experimental cases.

In Figure 4, for all experimental cases, graphs of the treated sludge shifted to the left compared to the graph of raw sludge. These results show that the particle sizes of the sludge treated by both treatment devices were reduced, i.e., both treatment devices decomposed the sludge particles. (Also, in both graphs, as energy consumption increases, the fraction of $100 \mu \mathrm{m}$ or more increased, however, this phenomenon was considered to be the result of flocculation during storage before particle size distribution measurement, hence it was neglected in this section.) Comparing the particle size distributions of the experimental cases, the typical particle sizes of the sludge treated by the ultrasonic bath were slightly smaller in case 1 . This result shows that, for low energy consumption, the particle disintegration performance of the ultrasonic bath was slightly superior to that of the HCR. However, in case 2, the fraction of the sludge particle treated by the HCR in the range under $10 \mu \mathrm{m}$ was significantly increased. This result shows that the particle disintegration performance of the HCR was much superior to that of the ultrasonic bath. In case 3, the fraction of sludge particle treated by the ultrasonic bath significantly increased compared to case 2, while the graph of HCR showed no more change. Finally, in case 4 , both graphs showed no more change.

For quantitative comparison, the particle size distributions as a percentile size (diameter of particle with a $10 \%$ volume fraction: $\mathrm{d}(0.1), 50 \%$ : d (0.5) and $90 \%$ : d (0.9)) are compared in Table 3 . The results show that $d(0.1)$ and $d(0.5)$ of the ultrasonic bath and the HCR were lower than those of raw sludge. In case $1, \mathrm{~d}(0.1)$ and $\mathrm{d}(0.5)$ of the ultrasonic bath were smaller than the those of the HCR. However, in case 2, d (0.5) of the HCR was $4.029 \mu \mathrm{m}$, decreased by $92.7 \%$ compared to raw sludge. In contrast, $d(0.5)$ of ultrasonic bath was $17.804 \mu \mathrm{m}$, reduced by $67.6 \%$ at the same energy consumption. The maximum reduction of the ultrasonic bath was $82.3 \%$ in case 4 having the highest energy consumption. As reference, a particle size reduction of $68 \%$ was achieved in a previous investigation using advanced oxidation processes (AOPs) [58]. This result shows overwhelming the particle decomposition performance of the HCR. The particle size distribution obtained from the sludge treated by the HCR indicated that there was no significant change after 10 treatments. This is considered to be due to the sludge decomposition reaching the final stage by the HCR in case 2 . However, for the sludge treated by the ultrasonic bath, the particle size distribution continued to change through case 3. Consequently, the final stage of particle decomposition was similar with the 
two devices; however, the HCR reached the final stage at a much lower specific energy input. Also, the final particle size of the sludge treated by the HCR was generally smaller.

Table 3. Percentile particle sizes.

\begin{tabular}{|c|c|c|c|c|}
\hline \multirow{2}{*}{\multicolumn{2}{|c|}{ Item }} & \multicolumn{3}{|c|}{ Percentile Size $(\mu \mathrm{m})$} \\
\hline & & d (0.1) & $\mathrm{d}(0.5)$ & $\mathrm{d}(0.9)$ \\
\hline \multicolumn{2}{|c|}{ Raw sludge } & 17.286 & 54.921 & 127.023 \\
\hline \multirow{2}{*}{ Case 1} & HCR & 6.116 & 34.737 & 101.324 \\
\hline & Ultrasonic bath & 4.558 & 30.647 & 257.734 \\
\hline \multirow{2}{*}{ Case 2} & HCR & 0.778 & 4.029 & 142.733 \\
\hline & Ultrasonic bath & 1.820 & 17.804 & 227.587 \\
\hline \multirow{2}{*}{ Case 3} & HCR & 0.865 & 5.719 & 161.269 \\
\hline & Ultrasonic bath & 0.941 & 13.999 & 682.707 \\
\hline \multirow{2}{*}{ Case 4} & HCR & 0.778 & 4.053 & 153.402 \\
\hline & Ultrasonic bath & 0.992 & 9.685 & 389.672 \\
\hline
\end{tabular}

To evaluate the uniformity of sludge decomposition, SVI results of the treated sludge are shown in Figure 5. In the result of HCR, settled sludge was observed only in cases 1 and 2, otherwise in the ultrasonic bath result, settled sludge was present in all experimental cases. Additionally, in case 1, the sedimentation amount of sludge treated by the HCR was about $1 / 3$ of the sludge treated by the ultrasonic bath. Since the settling occurs with particles over a certain size, it was confirmed that the HCR decomposed sludge particles more uniformly than the ultrasonic bath.

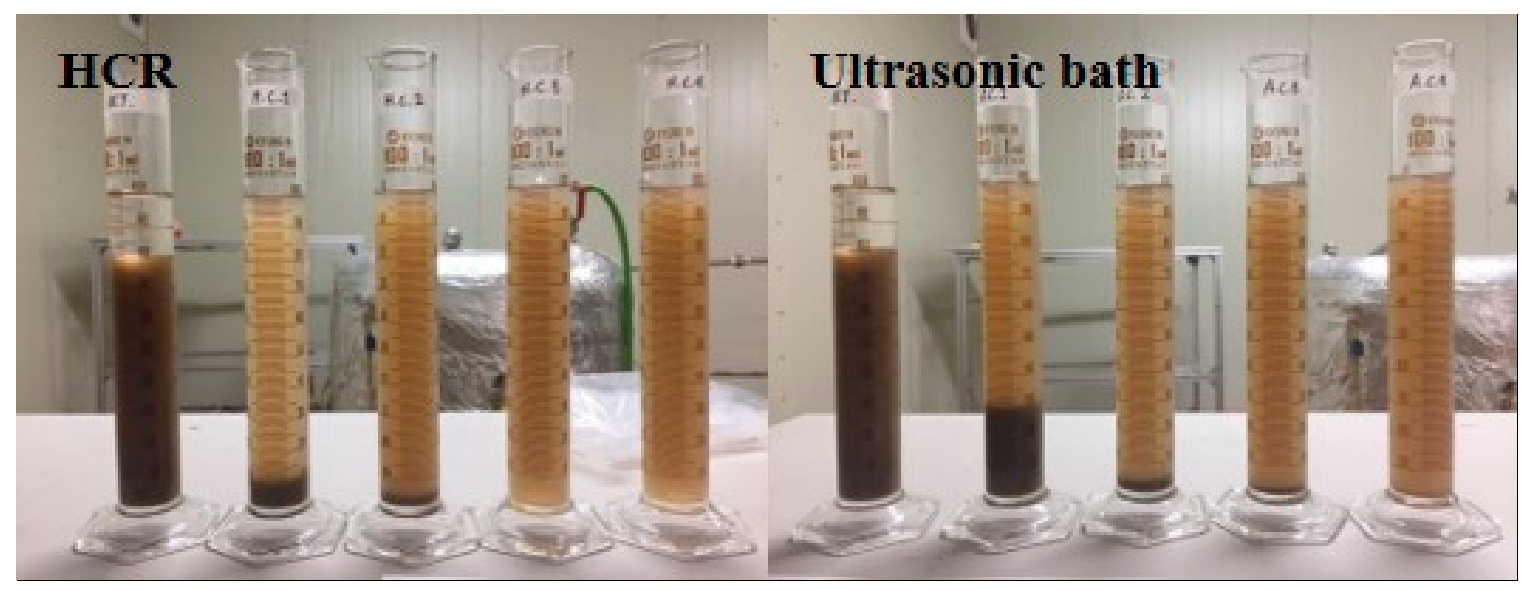

Figure 5. Sludge volume index (SVI) results for each of the experimental cases.

\subsection{Oxidation Performance}

As mentioned earlier, $\mathrm{OH}$. is generated when cavitation occurs. Often, cavitation intensity is expressed using the amount of generated $\mathrm{OH}$, e.g., the Weissler reaction [59]. In this section, the TCOD and VSS reduction rates were calculated to evaluate the oxidation performance of the type HCR, because both parameters are reduced by oxidation. The reduction rates were calculated as follows:

$$
\mathrm{TCOD}_{\mathrm{r}}(\%)=\frac{\mathrm{TCOD}_{\mathrm{m}}-\mathrm{TCOD}_{0}}{\mathrm{TCOD}_{0}} \times 100, \mathrm{VSS}_{\mathrm{r}}(\%)=\frac{\mathrm{VSS}_{\mathrm{m}}-\mathrm{VSS}_{0}}{\mathrm{VSS}_{0}} \times 100
$$

Here, the subscript $r$ represents the reduction rate, $m$ represents the measured value, and 0 represents the initial value. The TCOD and VSS reduction rates are shown in Figure 6. 

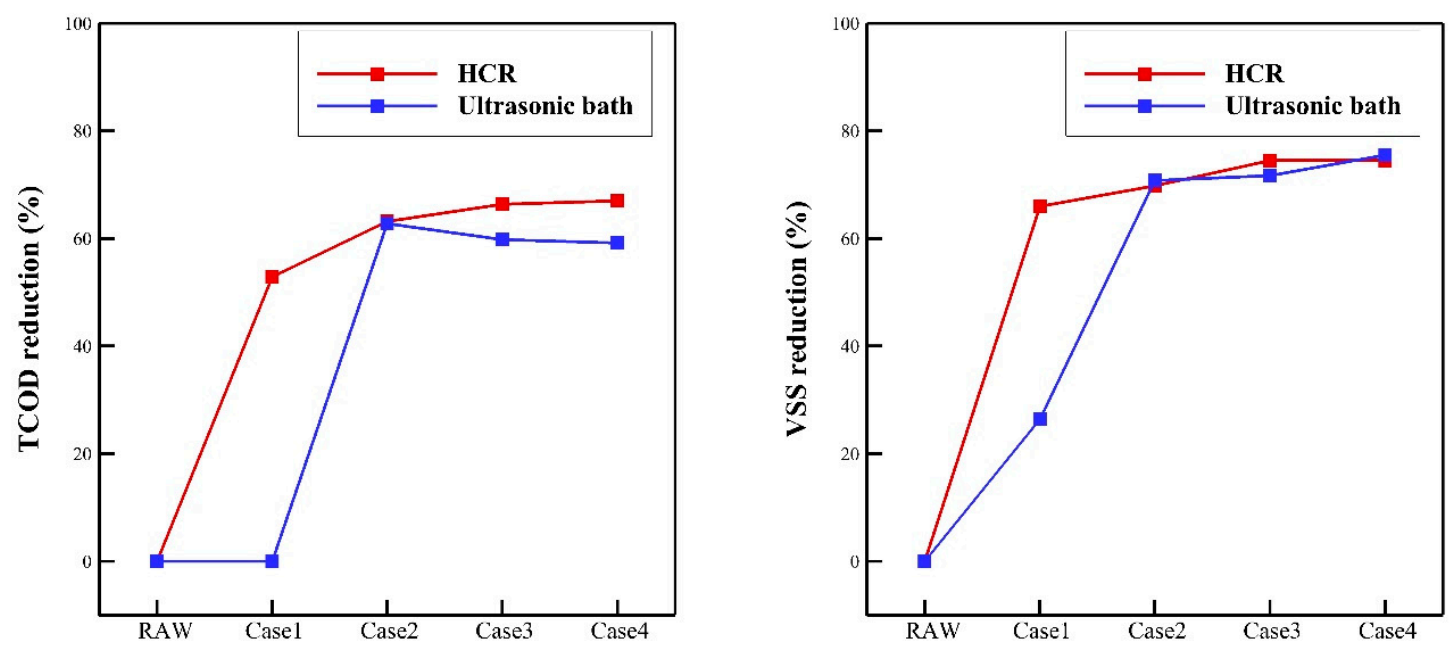

Figure 6. The total chemical oxygen demand (TCOD) and the volatile suspended solids (VSS) reduction rate.

As shown in Figure 6, the TCOD reduction rate of sludge treated by the HCR increased steadily. The TCOD is a parameter representing the amount of organic matter in sludge. Thus, a reduction of TCOD means that the amount of organic matter is reduced in the sludge. Since organic matter is reduced by oxidation, TCOD can serve as an indicator of oxidation. Namely, increasing the specific energy input of HCR increased oxidation. However, in case 1, the TCOD of the sludge treated by the ultrasonic bath was not reduced, i.e., oxidation did not occur. On the otherhand, in case 2, the TCOD reduction rate suddenly increased and was equal to that of sludge treated by the HCR. This result could be interpreted as follows. There is a certain level of threshold required to oxidize organic matter, and sudden oxidation occurs when that level is exceeded. This threshold could be determined by the amount of generated $\mathrm{OH}$. or energy needed for generating $\mathrm{OH}$. In any case, the oxidation performance of the HCR was remarkable superior to that of the ultrasonic bath. In case 3 and 4, the TCOD reduction rate of the sludge treated by the HCR converged, while the TCOD reduction rate of the sludge treated by the ultrasonic bath decreased. The oxidation of organic matter did not occur at more than a threshold level. The oxidation of organic matter proceeds due to a reaction of $\mathrm{OH}$. during cavitation [27]. The $\mathrm{OH} \cdot$ is a highly reactive oxidant and quickly disappears when there are no substances to oxidize. Therefore, when oxidation of organic matter in the sludge reached a particular level, the concentration of organic matter decreased, and the oxidation reaction did not actively occur even if $\mathrm{OH}$. was generated by the cavitation [19]. This circumstance was more pronounced in ultrasonic cavitation. As mentioned in the Introduction, ultrasonic cavitation occurs nearby to the ultrasonic terminal, and the cavitation intensity decreases with distance. As a result, the organic matter far from the ultrasonic generator cannot react with the $\mathrm{OH} \cdot$ generated by cavitation.

In Figure 6, the VSS reduction rate shows a similar trend with the TCOD reduction rate. The VSS reduction rate of sludge treated by the HCR increased as the specific energy input increases. In case 1 , the VSS reduction rate of sludge treated by the ultrasonic bath was about $25 \%$, demonstrating that oxidation occurred differently to the trend in the TCOD reduction rate. Otherwise, after this, the VSS reduction rate of both devices were similar. The VSS and TCOD are parameters indicating the amount of organic matter contained in sludge; however, the two parameters are not identical. Hence, these results should not be considered as conflicting but should be considered simultaneously to assess oxidation performance. In summary, in case 1, the oxidation of organic matter occurred only slightly within the sludge treated by the ultrasonic bath. The TCOD and VSS of sludge treated by both devices are quantitatively compared in Table 4. 
Table 4. Oxidization performance.

\begin{tabular}{ccccccc}
\hline \multicolumn{2}{c}{ Item } & RAW & Case 1 & Case 2 & Case 3 & Case 4 \\
\hline \multirow{2}{*}{ TCOD (mg/L) } & HCR & \multirow{2}{*}{4480} & 2110 & 1650 & 1505 & 1480 \\
& Ultrasonic bath & & 4482.5 & 1665 & 1800 & 1830 \\
\hline \multirow{2}{*}{ VSS (mg/L) } & HCR & \multirow{2}{*}{2120} & 720 & 640 & 540 & 540 \\
& Ultrasonic bath & & 1560 & 620 & 600 & 520 \\
\hline
\end{tabular}

Table 4 shows that the TCOD of the sludge treated by both devices were only similar in case 2 . On the other hand, the VSS of sludge treated by both devices displayed a clear difference only in case 1. Consequently, the sludge was oxidized by both devices, and potent oxidation performances were confirmed. However, in a low specific energy input condition, the oxidation performance of HCR was overwhelmingly superior to that of the ultrasonic bath. Also, oxidation of the sludge converged when the applied energy was beyond a specific threshold.

\subsection{Solubilization Performance}

The solubilization rate of the sludge was analyzed to evaluate the sludge treatment performance of the HCR. Solubilization of the sludge is the rate of soluble chemical oxygen demand (SCOD) of the TCOD. Solubilization is conducted by disintegration of organic matter contained in the sludge. The disintegration of organic matter entails cell lysis, resulting in increased hydrolysis and, consequently, an improvement in anaerobic digestion performance [60-62]. The solubilization rate is expressed as the ratio of TCOD and the increment of SCOD is calculated as follows [39]:

$$
\text { Solubilization rate }(\%)=\frac{\mathrm{SCOD}-\mathrm{SCOD}_{0}}{\mathrm{TCOD}_{0}-\mathrm{SCOD}_{0}} \times 100
$$

Generally, when sludge is disintegrated, SCOD and the solubilization rate increase. However, as discussed earlier, TCOD decreased due to oxidation in this study. Thus, to compare the solubilization rate according to the sludge decomposition, the $\mathrm{SCOD}_{\mathrm{m}}$ was normalized, and the solubilization was calculated as follows:

$$
\mathrm{SCOD}_{\mathrm{n}}=\frac{\mathrm{TCOD}_{0}}{\mathrm{TCOD}_{\mathrm{m}}} \times \mathrm{SCOD}_{\mathrm{m}}
$$

where the subscript $\mathrm{n}$ indicates the normalized value. The $\mathrm{SCOD}_{\mathrm{n}}, \mathrm{SCOD}_{\mathrm{n}}$, and solubilization rates are shown in Figure 7.
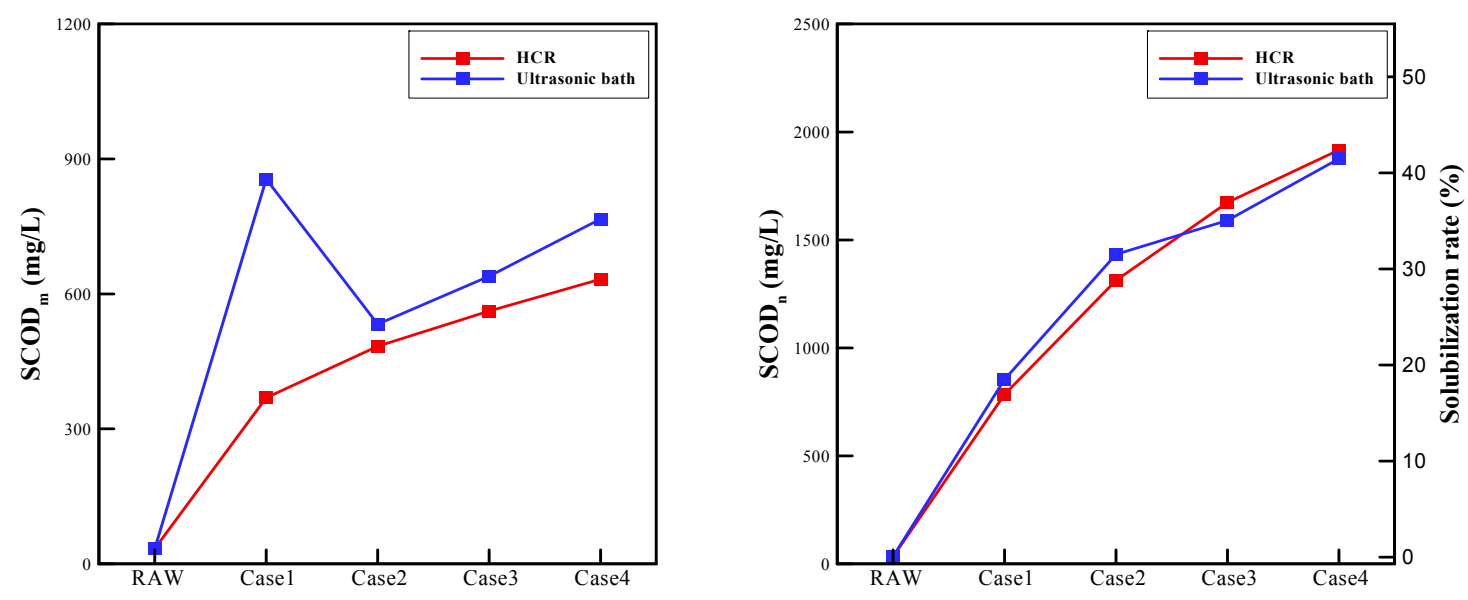

Figure 7. The measured soluble chemical oxygen demand (SCOD), nomalized SCOD, and solubilization rate. 
In Figure 7, the $\mathrm{SCOD}_{\mathrm{m}}$ of the sludge treated by HCR gradually increased with specific energy input. Otherwise, the $\mathrm{SCOD}_{\mathrm{m}}$ of the sludge treated by the ultrasonic bath was particularly high in case 1 and decreased in case 2, after which it then linearly increased with specific energy input. This is because, as discussed in Section 3.2, oxidation of sludge treated by the ultrasonic bath does not occur in case 1 . Namely, the organic matter contained in the sludge treated by the ultrasonic bath was only disintegrated and not oxidized in case 1; thus, the SCOD of the sludge sharply increased. Otherwise, the organic matter in the sludge treated by the HCR was disintegrated as well as actively oxidized in case 1; thus, the SCOD of the sludge slightly increased. As a result, the SCOD of the sludge treated by the ultrasonic bath was much greater than the SCOD of the sludge treated by the HCR in case 1 . In case 2 , the sludge treated by the ultrasonic bath was also oxidized, and the SCOD was reduced compared to that of case 1 . To avoid this circumstance, a normalized SCOD and solubilization rate were compared. Unlike the $\mathrm{SCOD}_{\mathrm{m}}$, the $\mathrm{SCOD}_{\mathrm{n}}$ and solubilization rate of sludge treated by both devices showed reasonable trends without abnormal values. In Figure 7, the $\mathrm{SCOD}_{\mathrm{n}}$ and the solubilization rate of sludge treated by the ultrasonic bath were higher than those of sludge treated by the HCR under a low specific energy input (case 1 and case 2); on the other hand, the $\mathrm{SCOD}_{\mathrm{n}}$ and solubilization rate of the sludge treated by HCR were higher under a high specific energy input (case 3 and case 4). To compare quantitative results, the values of $\mathrm{SCOD}_{\mathrm{m}}, \mathrm{SCOD}_{\mathrm{n}}$, and solubilization rate are shown in Table 5.

Table 5. Solubilization results.

\begin{tabular}{cccccc}
\hline & & Case 1 & Case 2 & Case 3 & Case 4 \\
\hline \multirow{2}{*}{ SCOD $_{\mathrm{m}}(\mathrm{mg} / \mathrm{L})$} & HCR & 369.5 & 483.5 & 562 & 633 \\
& Ultrasonic bath & 855 & 532.5 & 639 & 766.5 \\
\hline \multirow{2}{*}{$\mathrm{SCOD}_{\mathrm{n}}(\mathrm{mg} / \mathrm{L})$} & HCR & 784.5 & 1312.8 & 1672.9 & 1916.1 \\
& Ultrasonic bath & 854.5 & 1432.8 & 1590.4 & 1876.5 \\
\hline \multirow{2}{*}{ Solubilization rate (\%) } & HCR & 16.9 & 28.8 & 36.9 & 42.3 \\
& Ultrasonic bath & 18.5 & 31.5 & 35 & 41.4 \\
\hline
\end{tabular}

Except in case 1 , the $\mathrm{SCOD}_{\mathrm{m}}$ of sludge treated by the ultrasonic bath was $10 \%-20 \%$ higher than that of sludge treated by the HCR. However, when examining the results for $\mathrm{SCOD}_{n}$, the $\mathrm{SCOD}_{\mathrm{n}}$ for the ultrasonic bath treatment and the HCR showed similar values for all specific energy inputs. The solubilization rate also showed a similar trend, with that of sludge treated by the HCR reaching $42.3 \%$ at the highest specific energy input.

Solubilization of the sludge is accompanied by simultaneous particle decomposition and oxidation of organic matter. Consequently, although the particle decomposition and oxidation of the HCR were superior to those of the ultrasonic bath, due to contradictory interactions, the solubilization performance was similar in the two devices.

\section{Conclusions}

In the present work, to evaluate the WAS treatment performance of the rotor-stator type HCR, the performance was compared conducted with an ultrasonic bath using three assessment factors. The following conclusions were established from the present work.

- Particle decomposition of the rotor-stator type HCR is superior to that of the ultrasonic bath. After 10 treatments, the median particle size decreased by $92.7 \%$ in the rotor-stator type HCR, compared to a median particle size reduction of $67.6 \%$ at the same specific energy input in an ultrasonic bath. Also, through the results of SVI, it was discovered that the rotor-stator type HCR decomposed the sludge much more uniformly compared to the ultrasonic bath.

- A comparison of the TCOD and VSS reduction rates revealed that the rotor-stator type HCR had superior oxidation performance over the ultrasonic bath. In case 1, which had the lowest specific energy input, the rotor-stator type HCR reduced the TCOD and VSS by $53 \%$ and $66 \%$, respectively. 
On the other hand, the ultrasonic bath reduced the TCOD and VSS by $0 \%$ and $26 \%$, respectively. In case 4 , which had the highest specific energy input, the rotor-stator type HCR showed oxidation performance; the reduction rate of TCOD and VSS were calculated as $67 \%$ and $74 \%$, respectively.

- As shown through $\mathrm{SCOD}_{\mathrm{n}}$ and the solubilization rate, the two devices showed similar solubilization performance. Since particle disintegration and oxidation counteract each other, in case 1 and case 2 , the ultrasonic bath exhibited only a slightly higher solubilization rate. In contrast, the rotor-stator type HCR in case 3 and case 4 showed a slightly higher solubilization rate. In case 1 , which shows significant different oxidation performances, the $\mathrm{SCOD}_{\mathrm{m}}$ values were considerably different.

In the present paper, superior WAS treatment performance of the rotor-stator type HCR was revealed, especially at a low specific energy input. This result shows that the rotor-stator type HCR could be utilized as a more efficient WAS treatment device and may be of use even though the operating conditions in the present work were not optimized. Studies into the optimal conditions for the rotor-stator type HCR operation should be conducted. In the meantime, the rotor-stator type HCR can be utilized as an effective and environmentally friendly WAS treatment technique.

Author Contributions: Conceptualization, H.K. and J.Y.Y.; Methodology, H.K.; Formal Analysis, H.K. and X.S.; Investigation, H.K.; Resources, H.K. and J.Y.Y.; Data Curation, H.K. and B.K.; Writing-Original Draft Preparation, H.K., X.S., B.K., and J.Y.Y.; Supervision, J.Y.Y.

Funding: This work was supported by the National Research Foundation of Korea (NRF) grant funded by the Korean government (MSIT) (No. 2019R1F1A1061458).

Conflicts of Interest: The authors declare no conflict of interest.

\section{References}

1. Bagal, M.V.; Gogate, P.R. Wastewater treatment using hybrid treatment schemes based on cavitation and Fenton chemistry: A review. Ularason. Sonochem. 2014, 21, 1-14. [CrossRef]

2. Cvetković, M.; Kompare, B.; Klemenčič, A.K. Application of hydrodynamic cavitation in ballast water treatment. Environ. Sci. Pollut. R 2015, 22, 7422-7438. [CrossRef]

3. Holkar, C.R.; Jadhav, A.J.; Pinjari, D.V.; Mahamuni, N.M.; Pandit, A.B. A critical review on textile wastewater treatments: Possible approaches. J. Environ. Manag. 2016, 182, 351-366. [CrossRef]

4. Xu, P.; Zeng, G.M.; Huang, D.L.; Feng, C.L.; Hu, S.; Zhao, M.H.; Lai, C.; Wei, Z.; Huang, C.; Xie, G.X.; et al. Use of iron oxide nanomaterials in wastewater treatment: A review. Sci. Total Environ. 2012, 424, 1-10. [CrossRef] [PubMed]

5. Gogate, P.R.; Pandit, A.B. A review of imperative technologies for wastewater treatment I: Oxidation technologies at ambient conditions. Adv. Environ. Res. 2004, 8, 501-551. [CrossRef]

6. Ai, S.; Liu, H.; Wu, M.; Zeng, G.; Yang, C. Roles of acid-producing bacteria in anaerobic digestion of waste activated sludge. Front. Env. Sci. Eng. 2018, 12, 3. [CrossRef]

7. Zhen, G.; Lu, X.; Su, L.; Kobayashi, T.; Kumar, G.; Zhou, T.; Xu, K.; Li, Y.-Y.; Zhu, X.; Zhao, Y. Unraveling the catalyzing behaviors of different iron species $\left(\mathrm{Fe}^{2+} \mathrm{vs} . \mathrm{Fe}^{0}\right)$ in activating persulfate-based oxidation process with implications to waste activated sludge dewaterability. Water Res. 2018, 134, 101-114. [CrossRef] [PubMed]

8. Gogate, P.R. Treatment of wastewater streams containing phenolic compounds using hybrid techniques based on cavitation: A review of the current status and the way forward. Ularason. Sonochem. 2008, 15, 1-15. [CrossRef] [PubMed]

9. Patil, P.N.; Gogate, P.R.; Csoka, L.; Dregelyi-Kiss, A.; Horvath, M. Intensification of biogas production using pretreatment based on hydrodynamic cavitation. Ularason. Sonochem. 2016, 30, 79-86. [CrossRef] [PubMed]

10. Rayleigh, L., VIII. On the pressure developed in a liquid during the collapse of a spherical cavity. Philos. Mag. 1917, 34, 94-98. [CrossRef]

11. Suslick, K.S. Sonochemistry. Science 1990, 247, 1439-1445. [CrossRef] [PubMed]

12. Zieliński, M.; Dębowski, M.; Kisielewska, M.; Nowicka, A.; Rokicka, M.; Szwarc, K. Comparison of Ultrasonic and Hydrothermal Cavitation Pretreatments of Cattle Manure Mixed with Straw Wheat on Fermentative Biogas Production. Waste Biomass Valori. 2017, 10, 747-754. [CrossRef] 
13. Ruiz-Hernando, M.; Martinez-Elorza, G.; Labanda, J.; Llorens, J. Dewaterability of sewage sludge by ultrasonic, thermal and chemical treatments. Chem. Eng. J. 2013, 230, 102-110. [CrossRef]

14. Pawar, S.K.; Mahulkar, A.V.; Pandit, A.B.; Roy, K.; Moholkar, V.S. Sonochemical effect induced by hydrodynamic cavitation: Comparison of venturi/orifice flow geometries. AIChE J. 2017, 63, 4705-4716. [CrossRef]

15. Tao, Y.; Cai, J.; Huai, X.; Liu, B. A novel antibiotic wastewater degradation technique combining cavitating jets impingement with multiple synergetic methods. Ularason. Sonochem. 2018, 44, 36-44. [CrossRef]

16. Pilli, S.; Bhunia, P.; Yan, S.; LeBlanc, R.J.; Tyagi, R.D.; Surampalli, R.Y. Ultrasonic pretreatment of sludge: A review. Ularason. Sonochem. 2011, 18, 1-18. [CrossRef]

17. Jorand, F.; Zartarian, F.; Thomas, F.; Block, J.C.; Bottero, J.Y.; Villemin, G.; Urbain, V.; Manem, J. Chemical and structural (2D) linkage between bacteria within activated sludge flocs. Water Res. 1995, 29, 1639-1647. [CrossRef]

18. Sivakumar, M.; Pandit, A.B. Wastewater treatment: A novel energy efficient hydrodynamic cavitational technique. Ularason. Sonochem. 2002, 9, 123-131. [CrossRef]

19. Badve, M.; Gogate, P.; Pandit, A.; Csoka, L. Hydrodynamic cavitation as a novel approach for wastewater treatment in wood finishing industry. Sep. Purif. Technol. 2013, 106, 15-21. [CrossRef]

20. Gagol, M.; Przyjazny, A.; Boczkaj, G. Highly effective degradation of selected groups of organic compounds by cavitation based AOPs under basic $\mathrm{pH}$ conditions. Ularason. Sonochem. 2018, 45, 257-266. [CrossRef]

21. Milly, P.J.; Toledo, R.T.; Chen, J.; Kazem, B. Hydrodynamic cavitation to improve bulk fluid to surface mass transfer in a nonimmersed ultraviolet system for minimal processing of opaque and transparent fluid foods. J. Food Sci. 2007, 72, M407-M413. [CrossRef] [PubMed]

22. Milly, P.J.; Toledo, R.T.; Harrison, M.A.; Armstead, D. Inactivation of food spoilage microorganisms by hydrodynamic cavitation to achieve pasteurization and sterilization of fluid foods. J. Food Sci. 2007, 72, M414-M422. [CrossRef] [PubMed]

23. Milly, P.J.; Toledo, R.T.; Kerr, W.L.; Armstead, D. Hydrodynamic cavitation: Characterization of a novel design with energy considerations for the inactivation of Saccharomyces cerevisiae in apple juice. J. Food Sci. 2008, 73, M298-M303. [CrossRef] [PubMed]

24. Arrojo, S.; Benito, Y.; Tarifa, A.M. A parametrical study of disinfection with hydrodynamic cavitation. Ularason. Sonochem. 2008, 15, 903-908. [CrossRef] [PubMed]

25. Patil, L.; Gogate, P.R. Large scale emulsification of turmeric oil in skimmed milk using different cavitational reactors: A comparative analysis. Chem. Eng. Process. Process. Intensif. 2018, 126, 90-99. [CrossRef]

26. Yi, C.; Lu, Q.; Wang, Y.; Wang, Y.; Yang, B. Degradation of organic wastewater by hydrodynamic cavitation combined with acoustic cavitation. Ularason. Sonochem. 2018, 43, 156-165. [CrossRef]

27. Petkovšek, M.; Zupanc, M.; Dular, M.; Kosjek, T.; Heath, E.; Kompare, B.; Širok, B. Rotation generator of hydrodynamic cavitation for water treatment. Sep. Purif. Technol. 2013, 118, 415-423. [CrossRef]

28. Badve, M.P.; Gogate, P.R.; Pandit, A.B.; Csoka, L. Hydrodynamic cavitation as a novel approach for delignification of wheat straw for paper manufacturing. Ularason. Sonochem. 2014, 21, 162-168. [CrossRef]

29. Zupanc, M.; Kosjek, T.; Petkovšek, M.; Dular, M.; Kompare, B.; Širok, B.; Stražar, M.; Heath, E. Shear-induced hydrodynamic cavitation as a tool for pharmaceutical micropollutants removal from urban wastewater. Ularason. Sonochem. 2014, 21, 1213-1221. [CrossRef]

30. Šarc, A.; Kosel, J.; Stopar, D.; Oder, M.; Dular, M. Removal of bacteria Legionella pneumophila, Escherichia coli, and Bacillus subtilis by (super) cavitation. Ularason. Sonochem. 2018, 42, 228-236. [CrossRef]

31. Sun, X.; Kang, C.H.; Park, J.J.; Kim, H.S.; Om, A.S.; Yoon, J.Y. An experimental study on the thermal performance of a novel hydrodynamic cavitation reactor. Exp. Therm. Fluid Sci. 2018, 99, 200-210. [CrossRef]

32. Sun, X.; Park, J.J.; Kim, H.S.; Lee, S.H.; Seong, S.J.; Om, A.S.; Yoon, J.Y. Experimental investigation of the thermal and disinfection performances of a novel hydrodynamic cavitation reactor. Ularason. Sonochem. 2018, 49, 13-23. [CrossRef] [PubMed]

33. Cerecedo, L.M.; Dopazo, C.; Gomez-Lus, R. Water disinfection by hydrodynamic cavitation in a rotor-stator device. Ularason. Sonochem. 2018, 48, 71-78. [CrossRef] [PubMed]

34. Mancuso, G.; Langone, M.; Andreottola, G. A swirling jet-induced cavitation to increase activated sludge solubilisation and aerobic sludge biodegradability. Ularason. Sonochem. 2017, 35, 489-501. [CrossRef] [PubMed] 
35. Suenaga, T.; Nishimura, M.; Yoshino, H.; Kato, H.; Nonokuchi, M.; Fujii, T.; Satoh, H.; Terada, A.; Hosomi, M. High-pressure jet device for activated sludge reduction: Feasibility of sludge solubilization. Biochem. Eng. J. 2015, 100, 1-8. [CrossRef]

36. Nabi, M.; Zhang, G.; Zhang, P.; Tao, X.; Wang, S.; Ye, J.; Zhang, Q.; Zubair, M.; Bao, S.; Wu, Y. Contribution of solid and liquid fractions of sewage sludge pretreated by high pressure homogenization to biogas production. Bioresour. Technol. 2019, 286, 121378. [CrossRef]

37. Cai, M.; Hu, J.; Lian, G.; Xiao, R.; Song, Z.; Jin, M.; Dong, C.; Wang, Q.; Luo, D.; Wei, Z. Synergetic pretreatment of waste activated sludge by hydrodynamic cavitation combined with Fenton reaction for enhanced dewatering. Ularason. Sonochem. 2018, 42, 609-618. [CrossRef]

38. Grübel, K.; Suschka, J. Hybrid alkali-hydrodynamic disintegration of waste-activated sludge before two-stage anaerobic digestion process. Environ. Sci. Pollut. R 2015, 22, 7258-7270. [CrossRef]

39. Jung, K.W.; Hwang, M.J.; Yun, Y.M.; Cha, M.J.; Ahn, K.H. Development of a novel electric field-assisted modified hydrodynamic cavitation system for disintegration of waste activated sludge. Ularason. Sonochem. 2014, 21, 1635-1640. [CrossRef]

40. Fang, W.; Zhang, P.; Zhang, G.; Jin, S.; Li, D.; Zhang, M.; Xu, X. Effect of alkaline addition on anaerobic sludge digestion with combined pretreatment of alkaline and high pressure homogenization. Bioresour. Technol. 2014, 168, 167-172. [CrossRef]

41. Lee, I.; Han, J.-I. The effects of waste-activated sludge pretreatment using hydrodynamic cavitation for methane production. Ularason. Sonochem. 2013, 20, 1450-1455. [CrossRef] [PubMed]

42. Zhang, Y.; Zhang, P.; Zhang, G.; Ma, W.; Wu, H.; Ma, B. Sewage sludge disintegration by combined treatment of alkaline+high pressure homogenization. Bioresour. Technol. 2012, 123, 514-519. [CrossRef] [PubMed]

43. Zhang, S.; Zhang, P.; Zhang, G.; Fan, J.; Zhang, Y. Enhancement of anaerobic sludge digestion by high-pressure homogenization. Bioresour. Technol. 2012, 118, 496-501. [CrossRef] [PubMed]

44. Hirooka, K.; Asano, R.; Yokoyama, A.; Okazaki, M.; Sakamoto, A.; Nakai, Y. Reduction in excess sludge production in a dairy wastewater treatment plant via nozzle-cavitation treatment: Case study of an on-farm wastewater treatment plant. Bioresour. Technol. 2009, 100, 3161-3166. [CrossRef] [PubMed]

45. Petkovšek, M.; Mlakar, M.; Levstek, M.; Stražar, M.; Širok, B.; Dular, M. A novel rotation generator of hydrodynamic cavitation for waste-activated sludge disintegration. Ularason. Sonochem. 2015, 26, 408-414. [CrossRef] [PubMed]

46. Harris, P.W.; McCabe, B.K. Review of pre-treatments used in anaerobic digestion and their potential application in high-fat cattle slaughterhouse wastewater. Appl. Energy 2015, 155, 560-575. [CrossRef]

47. Bandelin, J.; Lippert, T.; Drewes, J.E.; Koch, K. Cavitation field analysis for an increased efficiency of ultrasonic sludge pre-treatment using a novel hydrophone system. Ularason. Sonochem. 2018, 42, 672-678. [CrossRef]

48. Kwon, W.C.; Yoon, J.Y. Experimental study of a cavitation heat generator. Proc. Inst. Mech. Eng. Part E J. Process Mech. Eng. 2013, 227, 67-73. [CrossRef]

49. Dewil, R.; Baeyens, J.; Goutvrind, R. Ultrasonic treatment of waste activated sludge. Environ. Prog. 2006, 25, 121-128. [CrossRef]

50. Tiehm, A.; Nickel, K.; Zellhorn, M.; Neis, U. Ultrasonic waste activated sludge disintegration for improving anaerobic stabilization. Water Res. 2001, 35, 2003-2009. [CrossRef]

51. Feng, X.; Lei, H.; Deng, J.; Yu, Q.; Li, H. Physical and chemical characteristics of waste activated sludge treated ultrasonically. Chem. Eng. Process. Process. Intensif. 2009, 48, 187-194. [CrossRef]

52. Mahmoud, N.; Zeeman, G.; Gijzen, H.; Lettinga, G. Solids removal in up flow anaerobic reactors, a review. Bioresour. Technol. 2003, 90, 1-9. [CrossRef]

53. Huan, L.; Yiying, J.; Mahar, R.B.; Zhiyu, W.; Yongfeng, N. Effects of ultrasonic disintegration on sludge microbial activity and dewaterability. J. Hazard. Mater. 2009, 161, 1421-1426. [CrossRef] [PubMed]

54. Liu, Y.; Wang, H.L.; Xu, Y.X.; Fang, Y.Y.; Chen, X.R. Sludge disintegration using a hydrocyclone to improve biological nutrient removal and reduce excess sludge. Sep. Purif. Technol. 2017, 177, 192-199. [CrossRef]

55. Wu, Z.; Yuste-Córdoba, F.J.; Cintas, P.; Wu, Z.; Boffa, L.; Mantegna, S.; Cravotto, G. Effects of ultrasonic and hydrodynamic cavitation on the treatment of cork wastewater by flocculation and Fenton processes. Ularason. Sonochem. 2018, 40, 3-8. [CrossRef] [PubMed]

56. Suslick, K.S.; Didenko, Y.; Fang, M.M.; Hyeon, T.; Kolbeck, K.J.; McNamara, W.B.; Mdleleni, M.M.; Wong, M. Acoustic cavitation and its chemical consequences. Philos. TR Soc. A 1999, 357, 335. [CrossRef] 
57. Zorba Gozde, T.; Sanin, F.D. Disintegration of Sludge by Sonication and Improvement of Methane Production Rates in Batch Anaerobic Digesters. CLEAN-Soil Air Water 2012, 41, 396-402. [CrossRef]

58. Kim, T.H.; Lee, S.R.; Nam, Y.K.; Yang, J.; Park, C.; Lee, M. Disintegration of excess activated sludge by hydrogen peroxide oxidation. Desalination 2009, 246, 275-284. [CrossRef]

59. Weissler, A.; Cooper, H.W.; Snyder, S. Chemical Effect of Ultrasonic Waves: Oxidation of Potassium Iodide Solution by Carbon Tetrachloride. J. Am. Chem. Soc. 1950, 72, 1769-1775. [CrossRef]

60. Bougrier, C.; Albasi, C.; Delgenès, J.P.; Carrère, H. Effect of ultrasonic, thermal and ozone pre-treatments on waste activated sludge solubilisation and anaerobic biodegradability. Chem. Eng. Process. Process. Intensif. 2006, 45, 711-718. [CrossRef]

61. Wu, Y.; Zhang, P.; Zeng, G.; Liu, J.; Ye, J.; Zhang, H.; Fang, W.; Li, Y.; Fang, Y. Combined sludge conditioning of micro-disintegration, floc reconstruction and skeleton building $\left(\mathrm{KMnO}_{4} / \mathrm{FeCl}_{3} /\right.$ Biochar $)$ for enhancement of waste activated sludge dewaterability. J. Taiwan Inst. Chem. E 2017, 74, 121-128. [CrossRef]

62. Wang, R.; Liu, J.; Hu, Y.; Zhou, J.; Cen, K. Ultrasonic sludge disintegration for improving the co-slurrying properties of municipal waste sludge and coal. Fuel Process. Technol. 2014, 125, 94-105. [CrossRef]

(C) 2019 by the authors. Licensee MDPI, Basel, Switzerland. This article is an open access article distributed under the terms and conditions of the Creative Commons Attribution (CC BY) license (http://creativecommons.org/licenses/by/4.0/). 